languages at https://www.eventure-online.com/eventure/www. pharos.nl/ingesprek

The films show multiple perspectives and therefore every family member, including the patient can identify. Watching the films in a migrant gathering or information meeting, in a family setting, or possibly together with a care provider, provides a good opening for a conversation about the needs, fears, and wishes of a patient. The films can be viewed as a whole, or in fragments (of just a few minutes), e.g. the fragment about disclosure or about pain relief.

Results We see that the films are conversation starters for both migrants and care providers. People are informed about supportive care and realize they can make choices.

Conclusions Pharos wants these films to be seen by many more people and 'spreads the word'. We would love to show the films at the congress, provide translation in English on the spot, and discuss their usefulness with the public.

\section{OP47 EXPERIENCES, KNOWLEDGE AND ATTITUDES OF INFORMAL CAREGIVERS REGARDING ADVANCE CARE PLANNING. A SYSTEMATIC REVIEW AND META SYNTHESIS OF QUALITATIVE STUDIES}

${ }^{1} \mathrm{~K}$ Silies*, ${ }^{2} \mathrm{R}$ Schnakenberg, ${ }^{3} \mathrm{H}$ Langner, 'S Köpke. 'University of Luebeck, Luebeck, Germany; ${ }^{2}$ Carl von Ossietzky University Oldenburg, Oldenburg, Germany; ${ }^{3}$ Martin-LutherUniversity Halle-Wittenberg, Halle (Saale), Germany

\subsection{6/spcare-2019-ACPICONGRESSABS.47}

Background Advance Care Planning (ACP) is a communication process about a person's preferences for treatment and care in case of physical or mental deterioration, when the person is unable to express these wishes. Trained health professionals act as facilitators and relatives may be involved. The aim of our review is to explore the experiences and attitudes of informal caregivers, and their knowledge regarding ACP.

Methods A systematic literature search was conducted (participants: informal caregivers, intervention: advance care planning; databases: MEDLINE, PsycINFO, CINAHL, Cochrane Library). Eligible studies were assessed by two independent reviewers. Quality appraisal was conducted using the Critical Appraisal Skills Programme (CASP) checklists. Thematic synthesis was applied for qualitative studies. Results from quantitative studies were associated to the meta categories of the thematic synthesis.

Results 41 studies met the inclusion criteria, of which 37 qualitative studies were included in the thematic synthesis. Major themes found were: "ACP-structures", "Roles and Relationships", "Perceptions of ACP", "Caregivers' Knowledge", "Attitudes". Barriers to and facilitators for ACP from the viewpoint of caregivers were described following the structure of the major themes. The importance of caregivers' role perceptions and the mutual influence of ACP and family relationships were highlighted.

Conclusion It is widely accepted, that ACP interventions have to take caregivers' points of view into account. Our review provides a rich description of caregivers' experiences, knowledge, attitudes, and needs regarding ACP. The results will support the development of patient- and family-centred ACP interventions and of instruments that measure effects of these interventions in caregivers.

\section{OP48 \\ PLANNING AHEAD WITH HEALTHCARE: PROXIES' NEEDS AND EXPERTS' RECOMMENDATIONS TO SUPPORT ADVANCE CARE PLANNING IN SWITZERLAND}

${ }^{1} \mathrm{~F}$ Bosisio*, ${ }^{2} \mathrm{~K}$ Karzig-Roduner, ${ }^{2} \mathrm{D}$ Drewniak, ${ }^{1} \mathrm{R}$ Jox, ${ }^{2} \mathrm{~T}$ Krones. ${ }^{1}$ Lausanne University Hospital, Lausanne, Switzerland; ' ZZurich university hospital, Zurich, Switzerland

\subsection{6/spcare-2019-ACPICONGRESSABS.48}

Background When there is no advance care planning (ACP), relatives feel uncomfortable and ambivalent when deciding on behalf of someone who has lost decision-making capacity. The aim of this study was to understand proxies' needs and gather experts' views on how to improve ACP in Switzerland.

Methods We conducted 20 interviews with proxies and four with experts in the three linguistic regions of Switzerland.

Results Half of the proxies were not familiar with ACP and spoke about living wills, testaments, and financial and organizational challenges of daily care. Only four people had the opportunity to advance decisions about healthcare with their kin when $\mathrm{s} / \mathrm{he}$ was diagnosed with a neurocognitive disease. Most interviewees became proxies by the circumstances and did not discuss their role further with the patient or other relatives. For most people, ACP was made difficult by caregivers not being explicit about disease progression and potential complications and proxies' role in future decision-making. When patients were very sick but still competent, professionals tended to exclude proxies albeit decisions had huge impact not only on the patient but also on their families. Communication and coordination with professionals and money are major concerns for most interviewees, in particular parents of disabled children. Experts' views are consistent with interviewees' experiences.

Conclusions Recommendations to improve ACP in Switzerland include increasing awareness in both professionals and the public, improving communication and coordination between professionals, patients and their proxies, better supporting relatives in their most urgent needs, and broaching ACP when discussing ongoing care plans.

\section{OP49 WELLBEING OF FAMILY CARERS OF PEOPLE WHO DIED OF CANCER: PRELIMINARY RESULTS OF THE ACTION ADVANCED CARE PLANNING (ACP) TRIAL}

${ }^{1}$ I Vandenbogaerde*, ${ }^{1} \mathrm{~A}$ de Vleminck, ${ }^{1} \mathrm{~J}$ Cohen, ${ }^{1} \mathrm{MN}$ Verkissen, ${ }^{2} \mathrm{~L}$ Lapeire, ${ }^{3} \mathrm{~F}$ Ingravallo, ${ }^{4} \mathrm{~S}$ Payne, ${ }^{5} \mathrm{~A}$ Wilcock, ${ }^{6} \mathrm{~J}$ Seymour, ${ }^{7} \mathrm{MC}$ Kars, ${ }^{8} \mathrm{U}$ Lunder, ${ }^{9} \mathrm{CA}$ Christensen, ${ }^{9} \mathrm{M}$ Grønvold, ${ }^{10} \mathrm{JAC}$ Rietjens, ${ }^{10} \mathrm{~A}$ van der Heide, ${ }^{1} \mathrm{~L}$ Deliens. 'Vrije Universiteit Brussel, Brussel, Belgium; ${ }^{2}$ Ghent University, Ghent, Belgium; ${ }^{3}$ University of Bologna, Bologna, Italy; ${ }^{4}$ Lancaster University, Lancaster, UK; ${ }^{5}$ Nottingham University Hospitals NHS Trust, Nottingham, UK; ${ }^{6}$ University of Nottingham, Nottingham, UK; ${ }^{7}$ University Medical Center Utrecht, Utrecht, Netherlands; ${ }^{8}$ University Clinic for Respiratory and Allergic Diseases, Golnik, Slovenia; ${ }^{9}$ University of Copenhagen, Copenhagen, Denmark; ${ }^{10}$ Erasmus MC, Rotterdam, Netherlands

\subsection{6/spcare-2019-ACPICONGRESSABS.49}

Background Previous studies showed that family carers (FCs) who engaged in formal ACP had fewer adverse outcomes in wellbeing compared with FCs who did not. The ACTION trial is the first multicentre randomized controlled trial of ACP in six European countries. This study will report on the effect of ACP on the wellbeing of bereaved FCs.

Methods 451 questionnaires were sent to bereaved FCs 3 months after the patient participating in the trial had died; 163 were returned (response rate: 36.1\%; $\mathrm{N}$ control= 93, $\mathrm{N}$ 
intervention $=70$ ). Wellbeing was measured with the Hospital Anxiety and Depression Scale (HADS) and Impact Event Scale (IES).

Results No significant differences were found in wellbeing of FCs between groups. The mean scores for the HADS show no significant differences between groups for anxiety (mean score control 7,09 vs. mean score intervention 8,29) and depression (mean score control 6,72 vs. mean score intervention 7,17). No significant differences are found between groups in the mean scores for the IES. Intrusion had a mean score of 21,27 for control vs. 21,38 for intervention; Avoidance had a mean score of 10,34 for control vs. 12,72 for intervention.

Conclusion Despite previous evidence about improved outcomes for wellbeing in FCs in ACP programs, our ACP intervention did not show differences between groups. Possibly the non-response or cultural discrepancies between the different countries have a part in this. More research is needed to explain what mechanisms are present.

This study is supported by a grant from the FWO (nr. G034717N).

\section{OP50 INFLUENCING FACTORS ON ENGAGEMENT IN ADVANCE CARE PLANNING (ACP) FROM THE CAREGIVER'S PERSPECTIVE}

S Herzog, M Koch, C Seifart. Philipps-University Marburg, Marburg, Germany

\subsection{6/spcare-2019-ACPICONGRESSABS.50}

Background One important aspect of successful ACP is the engagement of caregivers during the process. However, sometimes the engagement of patients and their caregivers in ACP is known to be difficult. Therefore barriers and facilitators of participation in ACP from the caregiver's point of view are explored.

Methods 12 relatives (caregivers) of palliative-oncologic patients were questioned in guideline-based interviews. 5 caregivers were children and 7 were spouses of patients. The analysis was conducted by Qualitative Content Analysis by $\mathrm{Ma}$ Recruiting patients yring. Two code trees were built: one posing a two-dimensional axis system made of plus and minus poles, the other one operating in the shape of clusters ("clouds") considering overlappings and connections of the six main themes ("stardust model").

Results Six result clusters were evaluated influencing the willingness of both patients and caregivers.

1. Skills Of ACP-Initiators (general and social expectations on the initiator and conductor of ACP-intervention)

2. "Omnipresent Electivity" (setting of daily-life impulses for ACP bearing a non-binding nature)

3. Importance of Relationship Between Spouses (understanding of symmetrical needs)

4. Relative Differences Of Perception Of Children And Spouses of patients

5. Maintenance of Objective Necessities (non-emotional structural circumstances such as resources of time, finances and legal responsibilities)

All empowering relatives to be

6. A Participative Caregiver (including experiences and desired role in ACP setting)

Conclusions Acknowledging the importance of caregivers and their essential role in ACP further interventions should consider incorporating these factors to improve the implementation of such.

\section{OP51 EXPERIENCES WITH AND OUTCOMES OF ADVANCE CARE PLANNING IN BEREAVED RELATIVES OF FRAIL OLDER PATIENTS: A MIXED METHODS STUDY}

${ }^{1}$ A Overbeek*, 'I Korfage, ${ }^{2} \mathrm{~B}$ Hammes, ${ }^{1} \mathrm{~A}$ van der Heide, 'J Rietjens. ${ }^{1}$ Erasmus MC, Rotterdam, Netherlands; ${ }^{2}$ C-TAC Innovations, La Crosse, USA

\subsection{6/spcare-2019-ACPICONGRESSABS.51}

Background Advance Care Planning (ACP) may prepare relatives of frail older patients for future decision-making.

Objective To investigate (1) how bereaved relatives of frail older patients experience ACP conversations and (2) whether ACP has an effect on relatives' preparation for decision-making and on their levels of anxiety and depression.

Design: Cluster randomised controlled trial.

Setting: Residential care homes in the Netherlands.

Subjects: Bereaved relatives of care home residents and community-dwelling frail older patients.

Methods We randomised 16 residential care homes to either the intervention group, where participants (frail older patients) were offered facilitated ACP, or the control group $(n=201)$, where they received 'care as usual'. If participants died, we approached relatives for an interview. We asked relatives who had attended ACP conversations for their experience with ACP (open-ended questions). Furthermore, we compared relatives' preparation levels for decision-making and levels of anxiety and depression (HADS) between groups. This trial was registered (NTR4454).

Results We conducted interviews with 39/51 (76\%) bereaved relatives (intervention group: $n=20$, control group: $n=19$ ). Relatives appreciated the ACP conversations. A few considered ACP redundant since they were already aware of the patient's preferences. Nine of 10 relatives in the intervention group felt adequately prepared for decision-making as compared to five of 11 relatives in the control group $(p=.03)$. Relatives' levels of anxiety and depression did not differ significantly between groups.

Conclusions In our study, bereaved relatives of frail older patients appreciated ACP. ACP positively affected preparedness for decision-making. It did not significantly affect levels of anxiety or depression.

\section{OP52 TO WHAT EXTENT DO ONLINE RESOURCES MEET THE NEEDS OF SUBSTITUTE DECISION-MAKERS IN AUSTRALIA? PART 2}

${ }^{1} \mathrm{M}$ Sellars*, ${ }^{1} \mathrm{~J}$ Tran, ${ }^{1} \mathrm{~L}$ Nolte, ${ }^{2} \mathrm{~B}$ White, ${ }^{3} \mathrm{C}$ Sinclair, ${ }^{4} \mathrm{D}$ Fetherstonhaugh, ${ }^{5} \mathrm{~K}$ Detering. ${ }^{7}$ Austin Health, MELBOURNE, Australia; ${ }^{2}$ Australian Centre of Health Law Research, Queensland University of Technology, Queensland, Australia; ${ }^{3}$ Rural Clinical School of Western Australia, University of Western Australia, Albany, Western Australia, Australia; ${ }^{4}$ Australian Centre for Evidence Based Aged Care, La Trobe University, Melbourne, Victoria, Australia; ${ }^{5}$ Faculty of Medicine, Dentistry and Health Science, University of Melbourne, Melbourne, Victoria, Australia

\subsection{6/spcare-2019-ACPICONGRESSABS.52}

Background We aimed to examine Australians' knowledge, attitudes and experiences regarding the role of substitute 